\title{
Ensino de Física moderna e contemporânea no Ensino Médio: o que pensam os envolvidos?
}

\author{
Jonas Guimarães Paulo Neto \\ Instituto Federal de Educação, Ciência e Tecnologia do Ceará - Campus Sobral (IFCE) \\ (jonasgui1@hotmail.com) \\ Antônio Nunes de Oliveira \\ Instituto Federal de Educação, Ciência e Tecnologia do Ceará - Campus Sobral (IFCE) \\ (nunesifsobral@gmail.com) \\ Marcos Cirineu Aguiar Siqueira \\ Instituto Federal de Educação, Ciência e Tecnologia do Ceará - Campus Maracanaú (IFCE) \\ (mcirineu@gmail.com)
}

\begin{abstract}
Resumo: A presente pesquisa aborda o ensino de Física no Ensino Médio (EM) contrastando as realidades vivenciadas por professores e alunos na medida em que se verificam as expectativas dos estudantes e seus desejos quanto à abordagem de Física Clássica (FC) e de Física Moderna e Contemporânea (FMC). Considerando a bibliografia existente sobre o tema, o trabalho partiu do interesse em conhecer as aspirações discentes sobre tópicos de FC e FMC para identificar os temas de FMC que os alunos já estudaram, assim como questões relacionadas ao ensino de Física. Para tanto, foi elaborado um questionário estruturado e aplicado aos alunos de quatro escolas da região norte do Ceará, sendo três públicas e uma particular, visando coletar suas concepções acerca do objeto de pesquisa. Observou-se que há um declínio sucessivo na preferência por tópicos de FMC ao longo das séries do EM e que no $1^{\circ}$ e $2^{\circ}$ ano a preferência por FMC supera a de FC. Constatou-se também que os livros didáticos nem sempre favorecem a compressão dos conteúdos e que cerca de $37 \%$ dos alunos questionados afirmam não conseguir entender ou aplicar os conteúdos de Física ensinados.
\end{abstract}

Palavras-chave: Física Clássica, Física Moderna e Contemporânea, Ceará.

Teaching modern and contemporary physics in high school: what do those involved think?

Abstract: The present research approaches the teaching of Physics in High School while contrasting the realities experienced by teachers and students and check the expectations of students along with their desires regarding the approach of Classical Physics (CP) and Modern and Contemporary Physics (MCP). Considering the existing bibliography on the subject, the work started from the interest in knowing the students' aspirations about CP and MCP topics and which MCP topics the students have already studied, as well as issues related to Physics teaching. For that, a structured questionnaire was elaborated and applied with students of four schools of the northern region of Ceará, being three public schools and one particular, aiming to collect their conceptions about the object of research. It was observed that there is a decline in preference for MCP topics and that in the 1st and 2nd year MCP preference overcomes CP. It was also found that textbooks do not always favor content compression and that about $37 \%$ of the students questioned say they can not understand or apply the physics contents taught there.

Key-words: Classical Physics, Modern and Contemporary Physics, Ceará. 


\section{INTRODUÇÃO}

A Física é dividida, segundo a tradição, em três grandes partes de acordo com a sua evolução histórica (DOMINGUINI, 2012). A primeira delas é a Física Clássica (FC), que compreende as teorias clássicas da Mecânica, Termodinâmica e do Eletromagnetismo, fundamentada nos trabalhos desenvolvidos por cientistas como Kepler (1571 - 1630), Galileu (1564 - 1642), Newton (1643 - 1727), Carnot (1796 - 1832), Gauss (1777 - 1855), Faraday (1791 - 1867), Ampère (1775 - 1836) e Maxwell (1831 - 1879). Em seguida, vem a Física Moderna (FM), que por sua vez originou-se das tentativas de explicar as assimetrias detectadas, no final do século $\mathrm{XIX}$, entre as teorias clássicas da Mecânica e do Eletromagnetismo e entre este último e os resultados experimentais da Termodinâmica. Os pressupostos básicos da FM (Teoria Quântica da Radiação e da Matéria e as Teorias da Relatividade) surgem a partir dos trabalhos revolucionários de cientistas como Max Planck (1858 1947), Albert Einstein (1879 - 1955), De Broglie (1891 - 1987), Niels Bohr (1885 1962), Erwin Schrödinger (1887 - 1961) e Werner Heisenberg (1901 - 1976). Por fim, vivenciamos atualmente a construção da chamada Física Contemporânea (FCO), que se desenvolve a partir dos fundamentos da FM e inclui, em seu campo de estudo, a investigação e discussão de assuntos como nanotecnologia, computadores quânticos, bóson de Higgs, ondas gravitacionais, dentre outros. A FCO não possui um marco teórico formalizado como a FM. Atualmente, consideramos que a FCO se iniciou em cerca da década de 40 do século passado, assim, as próximas gerações também vivenciarão a FCO. Trata-se, portanto, de uma "parte" da Física que é marcada pelo tempo em que a sociedade vive, de maneira contínua.

Comparando o estágio atual de desenvolvimento científico e tecnológico com a situação do ensino de Física nas escolas do Ensino Médio (EM), percebe-se por meio de uma análise panorâmica dos seus currículos que, embora estejamos no século XXI e que muitas descobertas relevantes e construções revolucionárias tenham sido concretizadas desde o final do século XIX, grande parte das escolas continuam com um currículo onde a Física ensinada é predominantemente (e quase que exclusivamente, em algumas escolas) aquela desenvolvida anteriormente ao século $\mathrm{XX}$, fato que pode trazer prejuízos aos estudantes quanto à compreensão do 
mundo atual. Segundo Terrazzan (1992), a maioria dos tópicos abordados em sala de aula são referentes à Física desenvolvida aproximadamente entre 1600 e 1850. Para Jardim, Guerra e Chrispino (2011):

Focada basicamente em estudos que vão pouco além da mecânica clássica, a Física do Ensino Médio não apresenta agentes motivadores para um aluno que se vê diante de uma física que não se dispõe à discussão ou modificações e, não lhe permite compreender a atualidade que lhe é exposta no cotidiano. Questões científicas mais interessantes a esse alunado podem ser encontradas na internet, revistas de divulgação, reportagens exibidas em telejornais e documentários na televisão (...), mas não em sala de aula. Essa distância parece incoerente com os interesses atuais. Além dos $\mathrm{PCN}+\mathrm{e}$ da motivação gerada nos alunos, os professores também compartilham as ideias do ensino de FMC nas salas de aula como importância de uma Física que é extremamente necessária para se entender as grandes inovações teóricas e tecnológicas atuais e que poderia trazer mais sentido ao aprendizado em sala de aula (JARDIM; GUERRA; CHRISPINO, 2011, p.3).

É preciso transformar o ensino de Física tradicionalmente oferecido nas escolas em um ensino que contemple o desenvolvimento da FM, não como uma mera curiosidade, mas como uma Física que surge para explicar fenômenos que a FC não consegue explicar, constituindo uma nova visão de mundo e, sobretudo, como uma Física que hoje é responsável pelo atendimento de necessidades que surgem a cada dia, tornando-se cada vez mais relevante para 0 homem contemporâneo. Nesse sentido, os vários campos abertos pela Física do século XX devem ter sua presença garantida nos currículos de nossas escolas de Ensino Médio (EM), particularmente a Física Quântica e a Física Relativística, que abriram novos horizontes de exploração científica inimagináveis aos olhos dos cientistas clássicos (PINTO; ZANETIC, 1999).

Para Júnior e Cruz (2003), várias propostas têm sido apresentadas objetivando a inclusão da Física Moderna e Contemporânea (FMC) no EM. Apesar disso, ainda há vários questionamentos acerca dessa inclusão:

Os tópicos de FMC devem apenas informar de forma que amplie a cultura cientifica dos alunos, ou pretende-se dar ao aluno todo o embasamento conceitual da FMC para que ele seja capaz de pensar e modelar os diversos temas que a constituem? Se o objetivo for mais formativo, qual a profundidade adequada par alunos do EM? (JÚNIOR; CRUZ, 2003, p. 1).

Ostermann e Moreira (1998), através de uma técnica de consulta conhecida como Delphi, tentaram estabelecer junto à comunidade brasileira de pesquisadores 
em ensino de Física, os tópicos de FMC que poderiam ser ensinados no EM, sendo eles: Efeito Fotoelétrico, Átomo de Bohr, Leis de Conservação, Radioatividade, Forças Fundamentais, Dualidade Onda-Partícula, Fissão e Fusão Nuclear, Origens do Universo, Raio-X, Metais e Isolantes, Semicondutores, Laser, Supercondutores, Partículas Elementares, Relatividade Restrita, Big-Bang, Estrutura Molecular, Fibras Ópticas.

Apesar de haver muitas considerações acerca da importância e da necessidade da presença de tópicos de FMC no EM, observa-se que muitas vezes não é possível essa presença por outras razões, como ressalta Menezes (2000):

É claro que precisa ser cautelosa a sinalização para a inclusão desses novos conteúdos, seja pelos desafios didáticos que implica, encontrando professores despreparados e os textos escolares desguarnecidos, seja porque as próprias universidades, ainda por algum tempo, continuarão a solicitar os velhos conteúdos em seus vestibulares. Será preciso algum tempo para que a mensagem seja, primeiro, compreendida e, mais tarde, aceita (MENEZES, 2000, p. 7).

Os conhecimentos de FMC podem despertar a curiosidade científica dos alunos e os motivar para aprender Física, e desta forma, compreender fenômenos que ocorrem ao seu redor. Se expostos de forma sistemática e experimental, dentro de uma perspectiva de aprendizagem significativa, os tópicos de FMC podem desenvolver no aluno a capacidade de observação e de análise de questões cotidianas relacionadas à Física, e ainda possibilitaria aos alunos uma reflexão sobre os fatos atuais (RENNER; KRUEGER, 2016).

Carvalho e Vannuchi (1996) defendem que o fator que deveria promover e influenciar a atualização dos currículos de Física no EM deveria estar relacionado com os grandes avanços conquistados por esta Ciência nas últimas décadas. Essas influências seriam, talvez, a porta de entrada para desfazer a contradição latente entre a vivência em um mundo cercado de novas tecnologias de última geração e um ensino de Física praticada por Galileu Galilei (1564 - 1642), Isaac Newton (1643 -1727), Georg Simon Ohm (1789 - 1854), por exemplo.

É importante dizer que este trabalho não tem por objetivo menosprezar os conteúdos de FC, pois ela continua válida e é de essencial conhecimento. O que se defende é mostrar aos alunos a evolução da Física, do conhecimento, transmitir para eles a ideia de que a Ciência está em constante construção. Terrazzan (1994, 
p. 70-71) corrobora afirmando que a inserção de tópicos de FMC no EM "não se trata, é claro, de abandonar o estudo da Física Clássica, mesmo porque, em muitos momentos, ela foi o suporte para o entendimento dos conceitos desenvolvidos na Física Moderna, a qual lhe sucedeu historicamente".

A presente pesquisa pretendeu saber dos estudantes do EM sobre seus interesses acerca de tópicos de FMC, assim como analisar a quantidade de alunos que já tiveram contanto com tais conteúdos. A relação com o livro didático também está intrinsecamente ligada ao trabalho. Dessa forma, a pesquisa pode contribuir com o processo de ensino-aprendizagem Física na medida que mostra a quantidade de estudantes que têm interesse em estudar conteúdos mais modernos e a quantidade dos que já estudaram.

\section{METODOLOGIA}

A pesquisa caracteriza-se como um estudo exploratório de caráter qualitativo que tem por interesse discutir as aspirações de discentes do EM acerca de tópicos de FMC e FC, além de pontos que permeiam o ensino de Física. Realizou-se mediante a elaboração e aplicação de um questionário estruturado aos alunos de todos os anos do EM de escolas públicas e particulares de quatro municípios do estado de Ceará. Seu objetivo foi coletar dados e opiniões dos educandos acerca da problemática deste trabalho e analisá-los de forma crítica, contrastando-os com as pesquisas na área.

A pesquisa foi atestada pelos representantes das escolas e envolveu 215 estudantes das três séries do EM. O quadro 1 denota a relação escola, local e sua natureza, particular ou pública. 
Quadro 1: Características das escolas participantes.

\begin{tabular}{|c|c|c|}
\hline Nome da Escola & Local & Natureza \\
\hline Escola A & Sobral & Particular \\
\hline Escola B & Forquilha & Pública \\
\hline Escola C & Irauçuba & Pública \\
\hline Escola D & Viçosa do Ceará & Pública \\
\hline
\end{tabular}

Fonte: Autores.

Inicialmente, elaborou-se um questionário com cinco questões direcionadas aos alunos do EM: a primeira questão objetivava saber deles quais conteúdos são postos por eles como de maior prioridade, na qual os estudantes marcaram de 1 a 20, onde os maiores números indicaram as maiores preferências e vice-versa, sendo possível assim verificar quais conteúdos de Física despertam neles maior interesse; a segunda tencionava conhecer quais conteúdos de FMC eles já estudaram, onde foram incluídos tópicos de FMC; a terceira trazia proposições acerca da Física estudada em suas escolas; a quarta pretendia tratar sobre a interdisciplinaridade das matérias do EM; e a quinta visava abordar acerca dos conteúdos de Física ministrados até então. As últimas três questões eram compostas por itens nos quais os alunos poderiam marcar como correto ou falso. A pesquisa ocorreu exclusivamente nas escolas analisadas e foi intermediada pelos professores.

Sobre os conteúdos de FMC que podem ser ensinados no EM, é importante citar que foi encontrada apenas a pesquisa realizada por Ostermann e Moreira (1998), a qual, embora tenha sido realizada há cerca de duas décadas, demonstrou enveredar por uma discussão bastante atual.

\section{RESULTADOS E DISCUSSÃO}

O gráfico 1 refere-se a análise feita das respostas à primeira pergunta e mostra os resultados dos dados obtidos após comparar as opções escolhidas pelos alunos participantes da pesquisa. Nela é possível perceber que no $1^{\circ}$ e no $2^{\circ}$ ano os alunos têm maior preferência por conteúdos de FMC, todavia a diferença cai do 1ํo para o $2^{\circ}$ ano. Já no $3^{\circ}$ ano, a opção por conteúdos de FC supera a de FMC. 
Gráfico 1: Comparativo entre os níveis de preferência quanto à aprendizagem de conteúdos de FC e FMC.

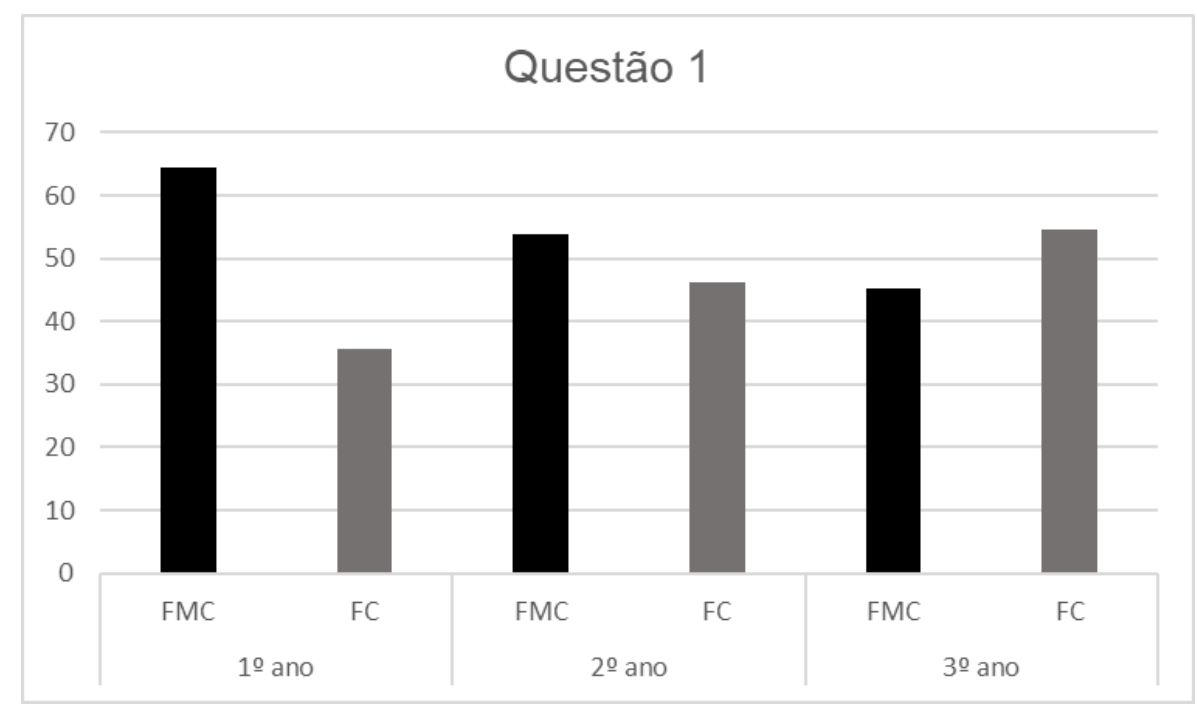

Fonte: Dados da pesquisa.

Os dados obtidos corroboram com as falas de Alves e Miltão (2014), Renner e Krueger (2016) e Torre (1998) quando eles ressaltam a necessidade de inserção de conteúdos de FMC no EM, uma vez que, conforme se percebe na pesquisa, é desejo dos discentes aprender sobre tais conteúdos, chegando a superar até mesmo suas expectativas quanto à aprendizagem de temas de FC.

Ao se comparar o fato reportado por D’Agostin (2008) e Menezes (2000), onde foram verificadas as dificuldades enfrentadas pelos professores do EM ao se deparar com a missão de ensinar conteúdos vinculados a FMC, e os resultados da pesquisa, conclui-se que a Física do EM não corresponde às expectativas de aprendizagem dos estudantes e, portanto, como afirmam Jardim, Guerra e Chrispino (2011) e Moreira (2011), ela se encontra defasada e descontextualizada, não tendo acompanhado a evolução científica e tecnológica do nosso século.

A queda na preferência dos alunos pela FMC em comparação com a FC, mostrado no gráfico 1 , quando se comparam as respostas dos alunos dos $1^{\circ}, 2^{\circ}$ e $3^{\circ}$ anos, consecutivamente, pode estar relacionada a fatos como:

- A má qualidade dos materiais de ensino, pois a maioria dos livros didáticos não traz informações com riqueza de detalhes sobre tais conteúdos. Não há conteúdos de FMC pré-estabelecidos para estarem presentes nas coleções de livros didáticos e nem para serem cobrados dos estudantes. Essa realidade, aliada ao fato de que, quando esses assuntos estão contidos nos livros eles costumam aparecer no final do último volume, colaboram para que 
o ensino de FMC não tome espaço nas escolas, pois o dilema entre tempo e conteúdo ainda persiste em sala de aula.

- Os tópicos de FMC não são ensinados como deveriam por conta da deficiência existente na formação dos professores, inicial e continuada, aliada ao tempo insuficiente que é disponibilizado para as aulas de Física, e à extensa programação curricular, principalmente nas escolas públicas, onde o número de aulas da disciplina é reduzido. Quanto à formação de professores, Ostermann e Moreira (2001, p. 146) questionam: "como queremos atualizar o currículo de Física das escolas de Nível Médio se não viabilizamos a atualização da própria formação inicial do professor?". Os autores ainda acrescentam que é fundamental preparar, nesse nível, os professores para a difícil tarefa de inovação curricular, se o objetivo é implementá-la nas escolas;

- Desmotivação dos professores frente aos baixos salários e à sobrecarga de atividades de preparação e aplicação de aulas e provas;

- Imagem preconcebida que os alunos têm da Física como algo impossível de se aprender;

- A partir do segundo ano do EM, o objetivo principal dos discentes torna-se, quase que completamente, a realização de uma boa prova de vestibular para garantir uma vaga na universidade. A não abordagem de tópicos de FMC em alguns programas dos vestibulares mais visados no país, como por exemplo o Exame Nacional do Ensino Médio (Enem), acarreta um desinteresse imediato nos estudantes pelos aprendizados relativos à FMC, uma vez que tais conteúdos não são focados nos exames. Segundo Zimermann (2018), os oito assuntos de Física que mais caem no Enem estão dentro dos tópicos: Mecânica, Eletricidade e Energia, Ondulatória, Termodinâmica e Óptica.

A segunda questão tencionou saber dos estudantes quais conteúdos eles já haviam estudado até o momento da pesquisa. Deste modo, seria possível concluir se alguns tópicos de FMC são ensinados no decorrer do EM ou se seu ensino segue a tradição didática, que aborda os conteúdos relativos à FMC no final do último livro (volume 3 das coleções didáticas).

A tabela 1 expressa a quantidade de alunos de cada ano que relataram já ter estudado os tópicos de FMC que foram listados. Nela pode-se perceber que apenas um tópico, Big Bang, foi estudado por mais da metade dos alunos. O segundo tópico que os alunos mais estudaram foi Radioatividade, com cerca de $32 \%$ do total de 
estudantes. Em seguida, vem a Astronomia com cerca de $21 \%$ das respostas. Infere-se ainda que os cinco tópicos restantes foram evidenciados com menos de $20 \%$ do total de alunos, dos quais dois não alcançaram nem 10\%, a saber, Relatividade Especial e Buracos Negros.

Tabela 1: Quantidade de alunos de cada ano que relataram já ter estudado os tópicos de FMC listados.

\begin{tabular}{|l|c|c|c|c|}
\hline Questão 2 & 1 ano & 20 ano & 3 ano & Total \\
\hline Relatividade Especial & 4 & 8 & 7 & 19 \\
\hline Relatividade Geral & 8 & 11 & 10 & 29 \\
\hline Radioatividade & 18 & 21 & 30 & 69 \\
\hline Big Bang & 50 & 28 & 37 & 115 \\
\hline Buracos Negros & 9 & 6 & 6 & 21 \\
\hline Astronomia & 13 & 15 & 18 & 46 \\
\hline Física Quântica & 6 & 12 & 10 & 28 \\
\hline Física Nuclear & 9 & 12 & 17 & 38 \\
\hline
\end{tabular}

Fonte: Dados da pesquisa.

Quase todos esses conteúdos estão presentes na listagem feita por Ostermann e Moreira (1998), citada anteriormente. Assim, esses conteúdos têm grande potencial para estarem presentes no EM. No entanto, observa-se que, nas escolas pesquisadas, poucos são incluídos e apenas dois se sobressaíram. Incluir os temas de FMC nos três anos do EM, sempre que possível, se mostra uma maneira eficiente de realizar essa inserção. Portanto, é necessário que haja propostas que visem essa introdução e que sejam adotadas pelos autores de livros didáticos, visando, dessa forma, que esses conteúdos sejam abordados de forma sequenciada nesse nível de ensino. Desse modo, o professor pode fazer links entre os conteúdos de FMC e FC, ou utilizar outra metodologia que julgar melhor, e o fato de esses tópicos estarem concentrados no final do volume 3 das coleções didáticas não será mais desculpa para que a FMC não seja ensinada no EM.

As respostas dos alunos alinham-se com o pensamento de Pereira e Aguiar (2006) e Alvetti (1999) quando afirmam que o ensino de Física no nível médio tem se limitado, principalmente, a temas da FC, pois dificilmente são trabalhados os conceitos da Física desenvolvidos no século passado, já que, conforme se pode observar nos dados, a grande maioria dos alunos não têm contato com assuntos 
relativos à FMC. Terrazzan (1992) colabora afirmando que, para uma grande maioria de estudantes, a Física discutida no EM será o único contato do estudante, na sua vida escolar formal, com os princípios físicos, então, qualquer que seja a interpretação dada, todos os aspectos da construção dos conhecimentos e teorias físicas necessitam ser contemplados no EM.

Loch (2011, p. 77) acrescenta que "o dilema entre quantidade e profundidade dos conteúdos, entre tentar cumprir o programa previsto para o Ensino Médio ou aprofundar alguns tópicos parece incomodar um pouco os professores [...]". Essa realidade é observada devido ao pouco tempo das aulas de Física, logo, os professores se veem obrigados a excluir alguns conteúdos e selecionar outros. Some-se a isso, o fato de que a ausência de materiais de apoio de FMC é muito enfatizada pelos professores quando se trata de sua inserção no EM.

Vale ainda ressaltar que os dois tópicos que tiveram maior quantidade de alunos são comuns a outras disciplinas. No caso, o Big Bang também é estudado na Biologia e a Radioatividade é estudada na Química. Embora ambos tenham abordagens diferentes dentro do escopo da Física, é certo que uma parte das respostas obtidas se deve originariamente a essas duas disciplinas, o que diminui ainda mais a quantidade de alunos que estudaram tópicos de FMC dentro da disciplina de Física.

A terceira questão versava sobre a opinião dos alunos acerca da disciplina de Física de uma forma ampla, na qual objetivava-se discutir sobre os conteúdos dos livros didáticos, a metodologia dos professores e a relação da Física com o cotidiano dos discentes. O gráfico 2 expressa os percentuais das respostas verdadeiro e falso de cada item da questão, com base nas respostas dos 215 alunos. 
Gráfico 2: Comparativo das proposições corretas e falsas segundo a opinião dos alunos

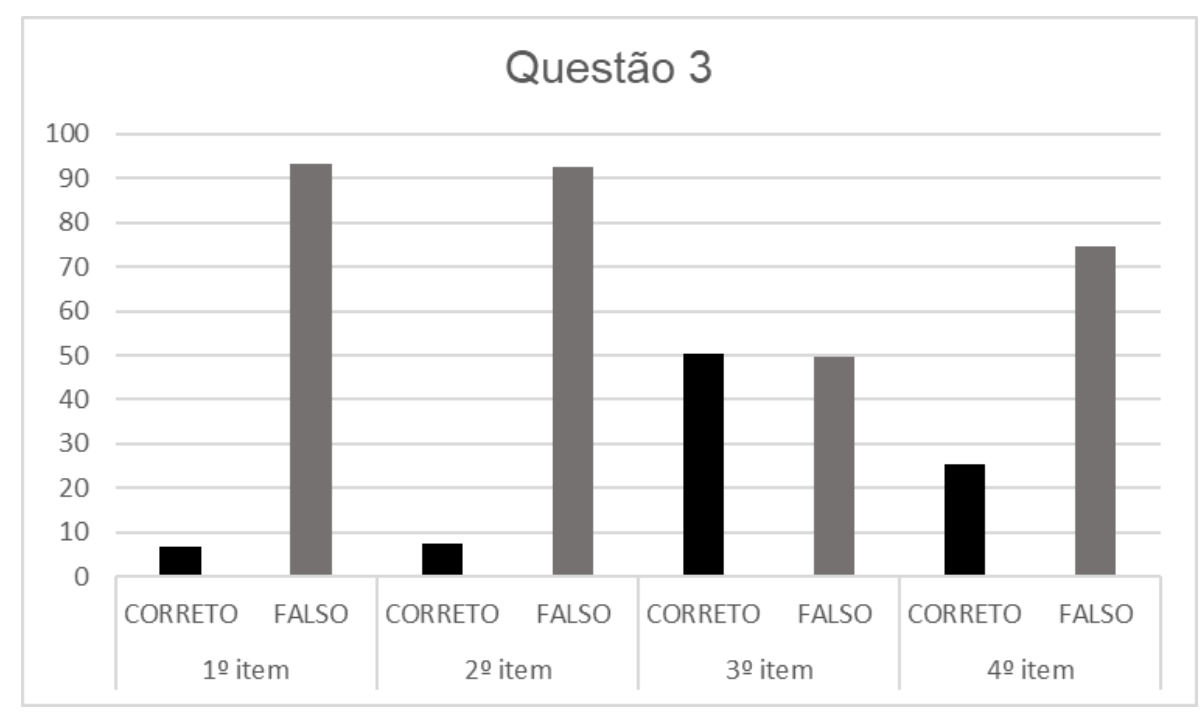

Fonte: Dados da pesquisa.

A proposição do primeiro item tinha como objetivo saber se é verdade que os alunos não sentem segurança da parte do professor quanto aos conteúdos de Física e, através do gráfico, conclui-se que a grande maioria, aproximadamente 93\%, assinalou o item como falso. Considerando o fato que foi constatado anteriormente de que a maioria dos alunos não têm contato com temas de FMC, conclui-se que esse percentual se refere aos conteúdos de FC. No que tange à preparação dos professores para lecionar conteúdos de FMC, Forquin (1993) defende que é muito importante a autonomia e participação do professor na confecção de propostas metodológicas pertinentes, assim como seu preparo em buscar sempre conhecimentos novos, pois a participação e capacitação do professor fica bem demonstrada a partir do fato de que "ninguém pode ensinar verdadeiramente se não ensina alguma coisa que seja verdadeira ou válida a seus próprios olhos", qualquer que seja a área de ensino (FORQUIN, 1993, p. 9). D'Agostin, Garcia e Leite (2007) garantem que os estudantes do EM estão preparados para receber conteúdos de FM. Entretanto, concluem que "é necessário antes disso dar subsídios para os professores para que eles possam trabalhar de forma significativa esses conceitos" (D'AGOSTIN; GARCIA; LEITE, 2007, p. 1).

O segundo item perguntava se os professores não possuem boa didática nas suas aulas. Observa-se novamente que a grande maioria, cerca de 92\%, apontou o item como falso, o que permite concluir que a didática dos professores não é um obstáculo à aprendizagem dos alunos. Os dados correspondem macroscopicamente à didática das aulas da disciplina de Física. Quando tratamos sobre o estudo de 
FMC, Forquin (1993) ratifica que a inclusão de conteúdos mais modernos no currículo escolar precisa ser cautelosa, pois novos conteúdos impõem novos desafios didáticos.

No terceiro item objetivou-se saber se os livros didáticos, na maioria das vezes, não favoreciam a compreensão dos conteúdos e se esses são repassados muito rapidamente na sala de aula. Através do gráfico, verifica-se que há um empate na quantidade de proposições verdadeiras com a quantidade de proposições falsas. Daí, conclui-se que a forma do livro didático usado, na qual se insere a abordagem dos conteúdos, a metodologia utilizada, a qualidade dos exercícios e aspectos gráficos, ou a maneira como ele está sendo usado atualmente podem ser empecilhos nas aulas de Física, levando a metade dos alunos a percebê-lo como um instrumento que não favorece o processo de ensino-aprendizagem. Esses números assessoram Souza (2002) quando certifica que os autores de livros didáticos dão excessiva ênfase aos vestibulares como forma de mostrar a sua preocupação com o futuro do aluno, acarretando uma confusão no julgamento crítico dos alunos ou até mesmo não permitindo que eles saibam diferençar adequadamente a Física da Matemática. Portanto, conclui-se que é necessária uma readequação dos livros didáticos para que eles possam atender às necessidades discentes, cabendo, nesse processo, a definição dos conteúdos de FMC pertinentes ao EM, a sua inserção e distribuição ao longo dos três volumes das coleções.

O quarto e último item dessa questão ambicionou saber dos alunos se a Física não estava relacionada com o cotidiano deles. Como se observa na figura, um percentual significativo dos respondentes, aproximadamente $25 \%$, indicou como correto, concluindo que a Física deve ser mais interligada com o dia a dia dos discentes, pois essa desconexão pode gerar um desinteresse por parte dos alunos, por não verem a aplicabilidade dos conteúdos. Os dados colaboram com Xavier (2005) quando afirma que muitos estudantes têm em mente a imagem de que a Física é algo impossível de se aprender, não reconhecendo até mesmo que ela é uma ciência experimental de grande aplicação no dia a dia. Dessa forma, ressalta-se a importância de relacionar a Física com o cotidiano dos alunos para que atribuam significado a cada um dos conceitos aprendidos em sala de aula. Os conteúdos de FMC são aplicáveis e passíveis de links com a realidade em que se vive tanto quanto os de FC, o que corrobora mais ainda o seu ensino no EM. 
A quarta questão versava sobre a interdisciplinaridade, na qual se almejava saber se os conteúdos das matérias das escolas do EM estão interligados, de forma que alguns deles sejam tratados simultaneamente em mais de uma matéria, ou se o conteúdo de uma disciplina complementa o de outra disciplina. O gráfico 3 mostra as porcentagens das respostas dos alunos para as proposições feitas.

Gráfico 3: Comparativo das proposições corretas e falsas sobre a interdisciplinaridade nas escolas de EM, segundo a opinião dos alunos pesquisados

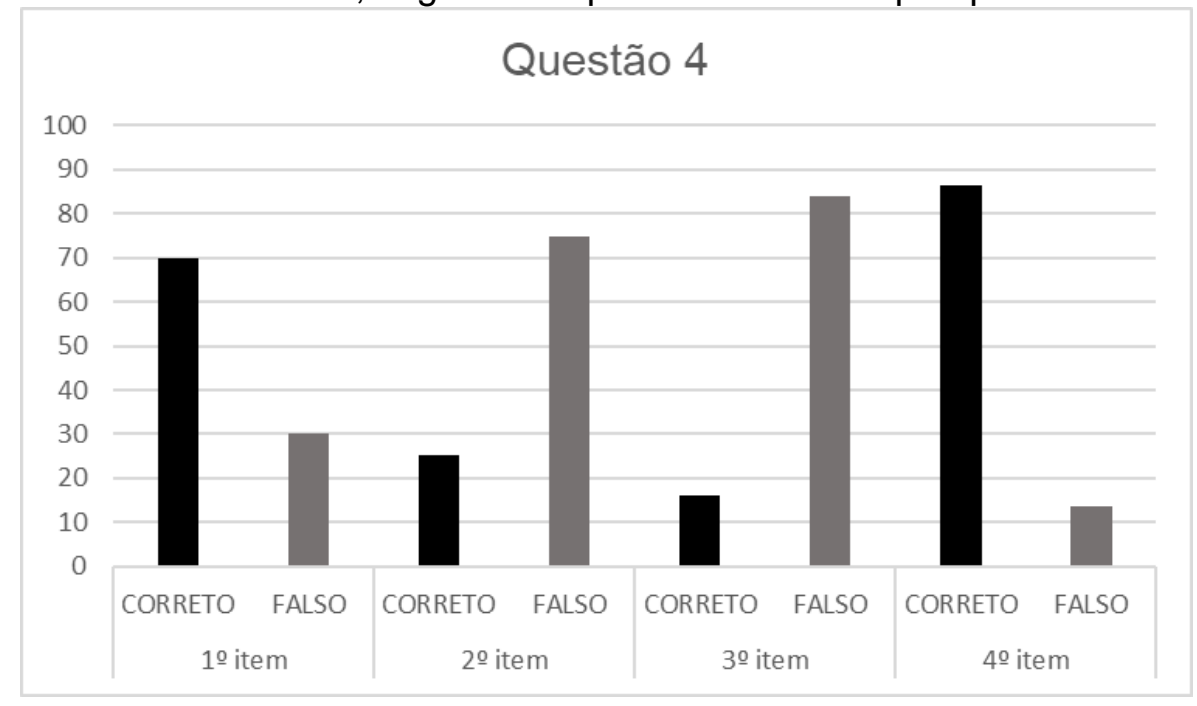

Fonte: Dados da pesquisa.

O primeiro item perguntava aos estudantes se alguns temas são tratados simultaneamente por professores das diversas matérias. Como mostra os dados, cerca de $70 \%$ dos alunos afirmam que alguns assuntos são tratados por mais de uma disciplina. As respostas dos estudantes concordam com os Parâmetros Curriculares Nacionais, PCN (BRASIL, 2000) quando orientam ao desenvolvimento de um currículo que contemple a interdisciplinaridade como algo que vá além da justaposição de disciplinas e, concomitantemente, evite a diluição das mesmas, de modo a se perder em generalidades. A interdisciplinaridade no ensino precisa "partir da necessidade sentida pelas escolas, professores e alunos de explicar, compreender, intervir, mudar, prever, algo que desafia uma disciplina isolada e atrai a atenção de mais de um olhar, talvez vários" (BRASIL, 2002, p. 88-89). Os dados ainda ilustram Bonatto et al. (2012) quando afirmam que a interdisciplinaridade é um elo entre o entendimento das disciplinas nas suas mais variadas áreas, constituindose importante, visto que abrangem temáticas e conteúdos, permitindo recursos inovadores e dinâmicos onde as aprendizagens são ampliadas.

O segundo item perguntava aos discentes se as matérias não se comunicam, se eles não veem relação entre elas, ou seja, se todas discorrem acerca de 
assuntos diferentes. Com um valor maior que o do item passado, mais de $74 \%$ dos estudantes marcaram como falso. Dessa forma, para a maioria dos alunos, há uma relação entre as disciplinas de sua grade curricular. Embora sejam matérias diferentes, algumas abordam o mesmo conteúdo com perspectivas diferentes, mas que se complementam. Os Parâmetros Curriculares Nacionais do Ensino Médio, PCNEM (BRASIL, 2002) agregam valor, garantindo que a interdisciplinaridade não tem a pretensão de criar novas disciplinas ou saberes, mas de utilizar os conhecimentos de várias disciplinas para resolver um problema ou compreender um determinado fenômeno sob diferentes pontos de vista. Bonatto et al. (2012) colaboram afirmando que, para ocorrer a interdisciplinaridade, não se trata de eliminar as disciplinas, e sim de torná-las comunicativas entre si, concebê-las como processos históricos e culturais e torná-las necessárias à atualização mútua quando se referem às práticas do processo de ensino-aprendizagem. A interdisciplinaridade implica um novo modo de pensar e agir, privilegiando a abertura para uma vivência interativa mediada por conhecimentos diversificados.

No terceiro item, o objetivo era saber dos alunos se eles acham as matérias interessantes, porém tendo dificuldades em todas. Observou-se que cerca de 16\% disseram que a proposição era correta. Considera-se o valor baixo, entretanto, isso significa que ainda há alunos que, embora achem os conteúdos da escola interessantes, têm dificuldades com todos. Quanto a essa questão, Oliveira, Andrade e Siqueira (2018) penhoram que um ponto em comum entre os professores é a preocupação em motivar os alunos para a aprendizagem, sendo esse um processo onde despertar o interesse para aprender se reveste de um clima de cumplicidade e forte conotação afetiva. Segundo Campos (1996), o achar difícil é a condição para o não gostar. Para o autor, há também uma relação de causa-efeito, contudo, em sentido contrário, na qual os alunos acham a Física um assunto maçante e, por isso mesmo, não se interessam em aprender, gerando dificuldade, ou seja, o não gostar implica o achar difícil, ao não querer entender. Sobre a Física, seu estudo revela que a dificuldade na disciplina é tida como natural, gerando nos alunos insegurança e medo, às vezes não decorrente da falta de estudo, mas de terem assimilado ou aceitado a Física como algo realmente difícil e que somente quem tem aptidão consegue aprender.

No quarto item buscou-se saber dos estudantes se eles acham as matérias do EM interessantes e têm afinidade apenas com algumas. Os dados mostram que 
mais de $86 \%$ dos discentes assinalaram como certo. Os números mostram que os alunos reconhecem a importância das disciplinas, porém não conseguem se identificar com todas, havendo preferências. Silva (2008) concorda afirmando que quando o aluno participa mais da aula, o conteúdo acaba se tornando menos complicado, cabendo ao professor fazer com que exista interesse e gosto pelo estudo da disciplina. Segundo o autor, o professor deve atentar para a motivação do aluno, aproveitando a oportunidade para mostrar a importância da disciplina para a vida do mesmo. No que tange à Física, tão ligada ao nosso cotidiano, Lara e Souza (2007) ratificam que relacionar o conhecimento ensinado ao cotidiano do aluno facilita o processo de ensino-aprendizagem, tornando esse conhecimento potencialmente significativo. Dessa forma, visto que os conteúdos de FMC são passíveis de muitas relações com o cotidiano, sua inserção no EM justifica-se como um fator preponderante para que os estudantes se interessem pelo estudo da Física.

A quinta questão versava sobre os conteúdos de Física ensinados nas escolas do EM. Desejava-se saber se há relação entre eles e o cotidiano dos discentes, conhecer a concepção e compreensão dos alunos acerca dos conteúdos estudados, verificar se conseguem associar a Física com as novas tecnologias e os desejos e aspirações dos estudantes sobre conteúdos novos e possíveis de compreender. O gráfico 4 representa as respostas objetivas dos alunos acerca das seis proposições feitas e a interpretação de cada uma vem em seguida.

Gráfico 4: Comparativo das proposições corretas e falsas acerca dos conteúdos de Física ensinados nas escolas

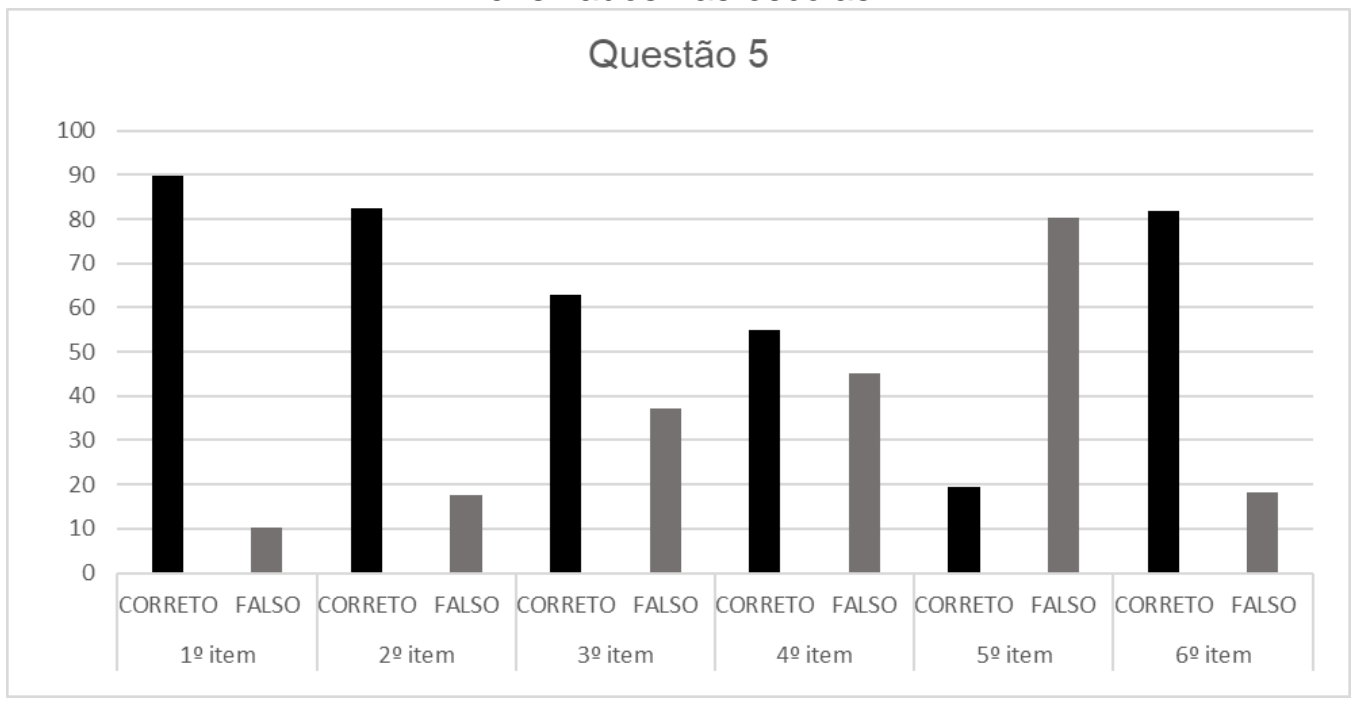

Fonte: Dados da pesquisa.

O primeiro item almejava saber dos alunos se os conteúdos de Física ensinados em sala de aula lhes possibilitam compreender os fenômenos do dia a 
dia. Como se pôde observar, quase $90 \%$ dos estudantes optou por correto. Os dados corroboram com Pereira e Aguiar (2006) quando citam que o cotidiano desempenha papel fundamental, pois o ensino de Física deve estimular ideias nos estudantes, permitindo-os pensar e interpretar o mundo que os cerca. No tocante ao ensino de FMC, os autores afirmam ainda que o cotidiano vivenciado pelos estudantes é fundamental na definição dos conteúdos relevantes de FMC. Pinto e Zanetic (1999) acrescentam que é preciso transformar o ensino de Física tradicionalmente oferecido nas escolas em um ensino que contemple o desenvolvimento da FM como uma Física que surge para explicar fenômenos que a FC não explica, constituindo uma nova visão de mundo e sendo responsável pelo atendimento de novas necessidades que surgem a cada dia.

O segundo item perguntava aos estudantes se os conteúdos de Física ensinados Ihes possibilitam compreender as tecnologias, as quais estão tão presentes na vida do homem atual. Cerca de $82 \%$ dos alunos assinalaram como correto. Alves e Miltão (2014) defendem que, com a inovação tecnológica e o fácil acesso às informações, o entendimento físico sobre determinados aparelhos corriqueiramente utilizados pela sociedade se torna fundamental. Essas tecnologias e seus embasamentos teóricos, em geral, levam os indivíduos ao desenvolvimento intelectual, adaptando-os às inovações do século XX e XXI. Grande parte dessas novas tecnologias não podem ser explicadas pela FC. Daí, faz-se necessária a inserção dos conceitos fundamentais de FMC no EM, capacitando os alunos a conhecerem mais sobre o significado físico associado aos bens, instrumentos e dispositivos que povoam o seu cotidiano.

No terceiro item, ambicionou-se saber se os alunos conseguem entender e aplicar os conteúdos ensinados de Física. Pelos dados do gráfico, constata-se que menos de $63 \%$ dos estudantes conseguem. Dessa forma, um percentual significativo de alunos ainda tem muita dificuldade em compreender os conceitos físicos, assim como em aplicá-los. Sobre isso, os PCNEM (BRASIL, 2000) colocam que

(...) espera-se que o ensino de Física, na escola média, contribua para a formação de uma cultura científica efetiva, que permita ao indivíduo a interpretação dos fatos, fenômenos e processos naturais, situando e dimensionando a interação do ser humano com a natureza como parte da própria natureza em transformação (BRASIL, 2000, p. 22).

Porém, na realidade, não é o que se observa. De acordo com Terrazzan (1994), 
Deve-se proporcionar aos estudantes uma visão da ciência física, por exemplo, como um corpo unitário de conhecimentos que possui uma estruturação interna em grandes sistemas conceituais interrelacionados. Assim, todos estes sistemas devem comparecer como conteúdos específicos de ensino na escola média, é claro com os recortes e as adequações metodológicas necessários para possibilitar a sua compreensão pelos estudantes. Aqui abre-se espaço de imediato para a introdução dos tópicos referentes à física moderna e contemporânea (TERRAZZAN, 1994, p. 162).

O quarto item buscou saber, na concepção dos alunos, se eles acham que os conteúdos de Física são bons, mas depois das provas esquecem, ou seja, embora reconheçam sua importância, a aprendizagem se dá de forma mecânica. Verificouse que quase 55\% declararam o item como verdadeiro. Segundo um texto da Universidade Católica de Brasília (UCB, 2018), na Aprendizagem Mecânica os novos dados e informações possuem pouca ou nenhuma associação com conceitos relevantes já disponíveis na estrutura mental, não sendo possível a interação entre eles. O conhecimento adquirido dessa forma será arbitrariamente distribuído pela estrutura cognitiva, sem "ligar-se" a conceitos subsunçores específicos nesta estrutura. Na teoria da Aprendizagem Significativa de Ausubel, os conceitos subsunçores são os conhecimentos prévios que os alunos já possuem no momento do aprendizado. Parisoto, Moreira e Moro (2012) citam que, na teoria desenvolvida por Ausubel, é imprescindível considerar o conhecimento que o aluno já possui para que ocorra de fato uma aprendizagem significativa e não mecânica, defendendo que o conhecimento apenas se constrói a partir da interação de conhecimentos antigos e novos. O resultado deste processo Ausubel chama assimilação.

No que diz respeito à FMC no EM, Ostermann e Moreira (2000) citam que a inserção dos conceitos básicos de FMC é de extrema relevância para os alunos do nível médio, possibilitando que o professor possa ensinar de forma significativa e interligando a Física da sala de aula com a Física do cotidiano. Os alunos do EM, mostram-se interessados em conhecer como funcionam algumas tecnologias que estão presentes no seu dia a dia, entre as quais destacam-se o GPS, a computação quântica, sensores fotoelétricos, entre outros. Todos esses exemplos necessitam da compreensão dos conceitos fundamentais de FMC e de sua importância para a sociedade de uma forma geral.

O quinto item procurou saber se os alunos não veem aplicação dos conteúdos ensinados, julgando-os como teorias e fórmulas, apenas. Os dados mostram que pouco mais de $80 \%$ dos estudantes julgou a proposição como falsa. Dessa forma, 
observa-se que os alunos reconhecem a aplicação da Física, assim como reconhecem que ela é importante na construção do seu conhecimento. Sendo assim, dado o reconhecimento de Física pelos educandos, Alvetti (1999) colabora salientando que as discussões a respeito da inserção da FM no EM vêm se acentuando com a justificativa de que a maioria dos alunos não ingressam no ensino superior após conclusão dessa etapa escolar, demonstrando que este estágio de aprendizado pode ser o único encontro sistematizado entre eles e o conhecimento advindo da FM. Pereira e Aguiar (2006) defendem que abordar temas de FM e a aplicação tecnológica dessa ciência na escola minimizaria os desafios relacionados à tecnologia, valendo-se deles para otimizar o processo de ensino-aprendizagem.

O sexto item tencionou saber se os discentes têm desejo de estudar os conteúdos relacionados às novas tecnologias, suas aplicabilidades e princípios. $O$ gráfico mostra que mais de $81 \%$ assinalou verdadeiro. Observa-se que há um desejo pulsante dos alunos por novos conteúdos de Física, conteúdos estes que ainda não são amplamente abordados em sala de aula como deveriam ser. Quanto a isso, Wilson (1992) corrobora afirmando que a inserção de FMC pode ser instigante para os jovens, pois não significa somente estudar o trabalho de cientistas que viveram centenas de anos atrás, mas também assistir cientistas falando na televisão sobre seus experimentos e expectativas para o futuro. Estudar problemas conceituais existentes na FMC envolve os estudantes nos desafios filosóficos de alguns aspectos da Física. O fato de que nem tudo, no mundo científico, é sabido ou entendido, modifica a ideia que os estudantes em geral têm de Física, um assunto que é uma "massa" de conhecimentos e fatos, um livro fechado. Ou são mostrados aos alunos os desafios a serem enfrentados pela Física no futuro, ou eles não serão encorajados a seguir carreiras científicas. $O$ autor defende que assuntos de FMC nas escolas pode provocar nos alunos o interesse pela carreira de Física e suas variações.

\section{CONSIDERAÇÕES FINAIS}

Para a realização desse trabalho, foi pesquisada a problemática da inserção de tópicos de FMC junto aos alunos do EM, tendo como objetivo geral obter 
informações acerca de suas preferências quanto aos temas de FMC e FC, acerca de quais assuntos foram estudados pelos alunos até o momento da pesquisa e se eles têm desejo de aprender novos conteúdos, bem como outras questões relacionadas à disciplina de Física, como a implementação prática das abordagens interdisciplinares e a relação dos seus conteúdos com o cotidiano. Para a sua concretização, foi aplicado um questionário estruturado a 215 alunos de quatro escolas da região norte do Ceará.

A pesquisa global possibilitou reafirmar a necessidade de reformulação do currículo de Física da educação básica com vistas a introduzir conteúdos de FMC, uma vez que os estudantes mostram interesse em estudá-los. Constatou-se também que dos oito tópicos de FMC constantes em tal currículo, apenas dois se sobressaíram, os quais são abordados interdisciplinarmente.

Cumpre, também, enfatizar a necessidade de análise dos motivos que levaram metade dos alunos a afirmarem que o livro didático não está contribuindo devidamente com o processo de ensino-aprendizagem, posto que sua compreensão, segundo a pesquisa, apresenta visível déficit.

Constatou-se que um percentual significativo de estudantes (25\%) ainda não vê relação entre a Física e o seu cotidiano. Tal fato está intrinsecamente ligado à falta de motivação dos alunos e pode ser a causa do fato de alguns alunos (37\%) terem afirmado não conseguirem entender e aplicar os conteúdos de Física ensinados na resolução de problemas. Portanto, visto a quantidade de estudantes que não conseguem relacionar a Física com o dia a dia, ressalta-se aqui o grande potencial que os tópicos de FMC têm de atrair os estudantes e relacionar o que se aprende em sala de aula com o mundo em que se vive.

A pesquisa também mostrou que $55 \%$ dos alunos julgam os assuntos de Física como bons, mas, depois das provas, esquecem os conteúdos. Portanto, entende-se que a aprendizagem de Física costuma se dar de forma mecânica, não contribuindo para a formação discente, e que alguma fase do processo de ensino e aprendizagem está sendo comprometida. A aversão à Física que muitos estudantes têm advém de fatos como esse, onde os estudantes são "obrigados" a decorar os conteúdos para a realização de testes escolares.

Salienta-se o poder da interdisciplinaridade na formação de um cidadão crítico, que percebe as relações e conexões daquilo que estuda e daquilo que o cerca, cuja presença foi constatada nas escolas pesquisadas. 
A maior parte dos estudantes (81\%) afirma ter curiosidade em estudar conteúdos que os possibilitem compreender os fenômenos do dia a dia e as novas tecnologias, conteúdos esses que se encontram dentro dos tópicos de FMC citados neste trabalho, aumentando ainda mais a sua importância e a necessidade de sua inclusão em ambientes reais de ensino, na educação básica.

Portanto, através dos dados do questionário aplicado aos alunos, pôde-se concluir que os estudantes do EM têm interesse em estudar conteúdos relacionados à $\mathrm{FMC}$, chegando ela a se sobressair frente à $\mathrm{FC}$ no $1^{\circ}$ e $2^{\circ}$ ano. No entanto, ainda é preciso desenvolver metodologias de ensino próprias para esses assuntos, pois alguns tópicos de FMC não são de compreensão simples como na FC, fazendo-se necessário que o professor saiba a "melhor" maneira de abordá-los e os torne mais "fáceis", e que pesquisadores da área de ensino de Física estabeleçam, junto aos autores das coleções didáticas, os temas que são pertinentes e devem estar presentes nesse nível de ensino, contribuindo para a formação de cidadãos críticos e antenados com o mundo em que vivem.

Uma das maneiras mais práticas de inserir a FMC de forma eficiente é sua distribuição nos três anos do EM, onde esses temas podem ser ensinados sempre que houver uma relação com conteúdos de FC, cabendo ao professor escolher a metodologia e julgar mais viável. Não é necessário esperar o fim do $3^{\circ}$ ano para se ensine FMC, pois muitas vezes os professores não conseguem dar conta de todo o conteúdo programático.

Considerando o caráter incessante da pesquisa por novos conhecimentos, propõe-se aqui algumas sugestões de continuidade para a abordagem feita neste trabalho:

- Estudar quais tópicos de FMC são pertinentes ao EM e podem estar presentes nas coleções dos livros didáticos de Física, visto que o último trabalho com esse objetivo foi realizado há 20 anos;

- Elaborar propostas para abordagem de tópicos de FMC que possibilitem a inserção de conteúdos específicos desses assuntos aliados aos de FC ou, em meio a eles, de forma a possibilitar disseminá-los ao longo dos três livros destinados ao EM. Propostas deste tipo podem tornar mais viável a abordagem da FMC nesse nível de ensino, uma vez que, na estrutura vigente, eles estão no último capítulo do último volume dos livros, aqueles 
que, segundo Oliveira e Almeida (2013), não dá tempo de serem abordados pelos professores, justamente por estarem dispostos no final do último livro.

\section{REFERÊNCIAS}

ALVETTI, M. A. S. Ensino de Física Moderna e Contemporânea e a revista Ciência Hoje. 1999. 170 f. Dissertação (Mestrado em Educação) - Universidade Federal de Santa Catarina, Florianópolis, 1999.

ALVES, Y. de M.; MILTÃO, M. S. R. Programa para formação continuada de professores na modalidade presencial: $O$ curso de Licenciatura em Física e a Física Moderna e Contemporânea. Caderno de Física da UEFS, Salvador, v. 12, n. 2, p. 11-20, jul./dez. 2014.

BONATTO, A. et al. Interdisciplinaridade no Ambiente Escolar. In: SEMINÁRIO DE PESQUISA EM EDUCAÇÃO DA REGIÃO SUL, 9., 2012, Caxias do Sul. Anais... Caxias do Sul: 2012.

BRASIL. Ministério da Educação. Parâmetros Curriculares Nacionais: Ensino Médio. Parte III Ciências da Natureza, Matemática e suas Tecnologias. Brasília: MEC/SEB, 2000.

. Ministério da Educação. Secretaria de Educação Média e Tecnológica.

Parâmetros Curriculares Nacionais: Ensino Médio. Brasília: Ministério da Educação, 2002.

CAMPOS, D. M. S. Metodologia do ensino da matemática. Rio de Janeiro: Vozes, 1996.

CARVALHO, A. M. P. de; VANNUCHI, A. O currículo de Física: inovações e tendências nos anos noventa. Investigações em Ensino de Ciências, Porto Alegre, v.1, n.1, p. 319, mar.1996.

D'AGOSTIN, A.; GARCIA, N. M. D.; LEITE, A. E. Física Moderna e Contemporânea no Ensino Médio: revisitando artigos de revistas. In: ENCONTRO NACIONAL DE PESQUISA EM ENSINO DE CIÊNCIAS, 6., 2007, Florianópolis. Anais... Florianópolis: ABRAPEC, 2007.

D'AGOSTIN, A. Física moderna e contemporânea: com a palavra professores do ensino médio. 2008. 112 f. Dissertação (Mestrado em Educação) - Universidade Federal do Paraná, Curitiba, 2008.

DOMINGUINI, L. Física moderna no Ensino Médio: com a palavra os autores dos livros didáticos do PNLEM. Revista Brasileira de Ensino de Física, São Paulo, v. 34, n. 2, p. 2502, jun. 2012.

FORQUIN, J. C. Escola e Cultura: As bases sociais e epistemológicas do conhecimento escolar. Tradução Guacira Lopes Louro. 1993. 208 f. Artes Médicas, Porto Alegre, 1993. 
JARDIM, W. T.; GUERRA, A.; CHRISPINO, A. Revisão de bibliografia: Física Moderna e sua relevância no Ensino Médio. In: SIMPÓSIO NACIONAL DE ENSINO DE FÍSICA, 18., 2011, Manaus. Atas... 2011.

JÚNIOR, M. R. F.; CRUZ, F. F. S. Física Moderna e Contemporânea no Ensino Médio: do consenso de temas à elaboração de propostas. In: ENCONTRO NACIONAL DE PESQUISA EM EDUCAÇÃO EM CIÊNCIAS, 4., 2003, Bauru. Atas... 2003.

LARA, A. E.; SOUSA, C. M. S. G. A construção de apresentações em slides como material potencialmente significativo, visando a facilitação da aprendizagem significativa em conteúdos de Física: o tópico de Colisões. In: ENCONTRO NACIONAL DE PESQUISA EM ENSINO DE CIÊNCIAS, 6., 2007, Florianópolis. Atas... 2007.

LOCH, J. Física Moderna e Contemporânea no planejamento de professores de Física De Escolas Públicas do Estado do Paraná. 2011. 119 f. Dissertação (Mestrado em Educação) - Universidade Federal do Paraná, Curitiba, 2011.

MENEZES, L. C. de. Uma física para um novo ensino Médio. Revista Física na Escola, São Paulo, v. 1, n. 1, out. 2000.

MOREIRA, M. A. Aprendizagem Significativa: a teoria e textos complementares. São Paulo: Editora Livraria da Física, 2011.

OLIVEIRA, A. N.; ALMEIDA, C. A. S. Ensino de Relatividade Especial no Ensino Médio: uma abordagem progressiva. In: LIMA, I. B. org. Didática, Educação Ambiental e Ensino de Ciências e Matemática: múltiplos olhares, II: didática e ensino de ciências e matemática, p. 107-117. Fortaleza: Editora UECE, 2013.

OLIVEIRA, A. N de; ANDRADE, P. A. A; SIQUEIRA, M. C. A. A motivação em sala de aula: o que dizem os alunos sobre as aulas de Física do Ensino Médio? ScientiaTec: Revista de Educação, Ciência e Tecnologia do IFRS, v.5, n.2, p: 130-150, jul./dez. 2018.

OSTERMANN, F.; MOREIRA, M. A.; Tópicos de Física Contemporânea na Escola Média: um Estudo com a Técnica Delphi. In: Encontro de Pesquisadores em Ensino de Física, 6., 1998, Florianópolis. Atas...1998.

OSTERMANN, F.; MOREIRA, M. A. Uma revisão bibliográfica sobre a área de pesquisa "física moderna e contemporânea no ensino médio". Investigação em Ensino de Ciências, Porto Alegre, v. 5, n. 1, p. 23-48, mar. 2000.

OSTERMANN, F.; MOREIRA, M. A. Atualização do currículo de Física na escola de nível médio: um estudo dessa problemática na perspectiva de uma experiência em sala de aula e da formação inicial de professores. Caderno Catarinense de Ensino de Física, Florianópolis, v. 18, n. 2, p. 135-151, 2001.

PARISOTO, M. F.; MOREIRA, M. A.; MORO, J. T. Subsunçores para a Física aplicada à Medicina, no contexto do Ensino de Física. Ensino, Saúde e Ambiente, Niterói, v. 5, n. 1, p. 43-62, abr. 2012.

PEREIRA, D. R. de O; AGUIAR, O. Ensino de Física no nível médio: tópicos de Física Moderna e Experimentação. Revista Ponto de Vista, Florianópolis, v. 3, p. 65-81, 2006. 
PINTO, A. C.; ZANETIC, J. É possível levar a Física Quântica para o Ensino Médio? Caderno Catarinense de Ensino de Física, Florianópolis, v. 16, n. 1, p. 7-34, 1999.

RENNER, G. L. P.; KRUEGER, C. Física Moderna e Contemporânea no Ensino Médio: Um estudo acerca dos fatores que interferem na aplicação dos conceitos relacionados em sala de aula. In: Simpósio Nacional de Ensino de Ciências e Tecnologia, 5., 2016, Ponta Grossa. Atas... 2016.

SILVA, C. O. da. A concepção de alunos do ensino médio sobre a matemática em uma escola pública do município de Porto Alegre. 2008. 40 f. Trabalho de Conclusão do Curso (Licenciatura Plena em Matemática) - Pontifícia Universidade Católica do Rio Grande do Sul, Porto Alegre, 2008.

SOUZA, T. C. F. de. Avaliação do ensino de Física: um compromisso com a aprendizagem. Passo Fundo: UPF Editora, 2002.

TERRAZZAN, E. A. A inserção da Física Moderna e Contemporânea no Ensino de Física na escola de 2 grau. Caderno Catarinense de Ensino de Física, Florianópolis, v. 9, n. 3, p. 209-214, dez. 1992.

TERRAZZAN, E. A. Perspectivas para a Inserção da Física Moderna na Escola Média. 1994. 241 f. Tese (Doutorado em Educação) - Faculdade de Educação, Universidade de São Paulo, São Paulo 1994.

TORRE, A. C. de la. Reflexões sobre o ensino da física moderna. Educacion en Ciências, v. 2, n. 4, p. 70-71, 1998.

WILSON, B. Particle physics at A-level - a theacher's viewpoint. Physics Education, Bristol, v. 27, n. 2, p. 64-65, mar. 1992.

Universidade Católica de Brasília (UCB). Aprendizagem Mecânica. [S.I.], [S.d.]. Disponível em: <https://cae.ucb.br/tas/tas/tas09.html>. Acesso em: 18 de mar. de 2018.

XAVIER, J. C. Ensino de Física: presente e futuro. In: Simpósio Nacional Ensino de Física, 16., 2005, Rio de Janeiro. Atas... 2005.

ZIMERMANN, Dara. Os 8 assuntos de física que mais caem no Enem. Pró Universidade, [S.I.], 4 maio 2018. Disponível em: <https://prouniversidade.com.br /aulasonline/blog/os-8-assuntos-de-fisica-que-mais-caem-no-enem/>. Acesso em: 10 dez. 2018. 